\title{
Metabolic Changes in Deafferented Central Neurons of an Insect, Acheta domesticus. II. Effects on Cholinergic Binding Sites and Acetylcholinesterase
}

\author{
Mark R. Meyer, G. Rajarami Reddy, ${ }^{1}$ and John S. Edwards \\ Department of Zoology, University of Washington, Seattle, Washington 98195
}

Following the finding that cercal deafferentation of developing giant interneurons in the terminal abdominal ganglion (TG) of the cricket Acheta domesticus reduces TG protein metabolism within target interneuron dendrites and somata (Meyer and Edwards, 1982), it is now shown that deafferentation alters the turnover of three macromolecules associated with cholinergic transmission in the cercal sensory-giant interneuron pathway.

The labeled specific ligands ${ }^{3} \mathbf{H}$-quinuclidinyl benzilate and ${ }^{125} I-\alpha$-bungarotoxin were used to assay populations of putative TG muscarinic and nicotinic cholinergic receptors, respectively, in control and deafierented groups of ganglia. The AChE activity of TG was also determined by assay and histochemical methods.

Long-term deafierentation sustained throughout postembryonic development markedly reduces the densities of both muscarinic and nicotinic binding sites in the TG; short-term deafferentation of adult TG also leads to characteristic alterations in the properties of all three cholinergic markers within several days. Rapid changes seen in adults thus correlate with ultrastructural data demonstrating loss of afferent terminals within hours of sensory appendage removal.

We propose that peripheral innervation-dependent regulatory mechanisms operate in both the developing and adult insect nervous system. Such mechanisms may influence transsynaptically the synthesis and turnover of specific macromolecules, some of which may reside on the cell surface of insect central neurons that are part of the cercal sensory-giant interneuron system.

Central neurons vary widely in response to the removal of their presynaptic terminals or postsynaptic targets. Some undergo swift degeneration, while others appear to be unaffected (Cowan, 1970; Smith, 1977). Insect central neurons, like their vertebrate counterparts, often seem more vulnerable to the effects of denervation during development (for review, see Edwards and Meyer, 1985), but the capacity for plasticity does not cease with maturity (Pitman and Rand, 1982; Roederer and Cohen, 1983). Where axotomy or deafferentation does affect the growth or maintenance of insect central neurons, it is likely that they are strongly influenced by local factors or growth cues provided by afferent terminals or postsynaptic target cells (Hoy et al., 1978; Schneiderman et al., 1982; Shankland et al., 1982).

The effects of deafferentation on the properties of identifiable giant interneurons in the terminal abdominal ganglion of the cricket Acheta domesticus (Fig. 1) have been characterized in detail (Murphey and Levine, 1980; Murphey et al., 1975; Palka

Received Aug. 14, 1985; revised Oct. 21, 1985; accepted Oct. 30, 1985.

This work was supported by NIH Grant \#NB-0778 and the Graduate School Research Fund; G.R.R. was the recipient of a Government of India postdoctoral fellowship.

Correspondence should be addressed to Mark R. Meyer, Department ofZoology NJ-15, University of Washington, Seattle, WA 98195.

I Present Address: S.V.U.P.G. Centre, Kavali, A.P., India.

Copyright (C) 1986 Society for Neuroscience $0270-6474 / 86 / 061676-09 \$ 02.00 / 0$ and Edwards, 1974). These cells respond to removal of cercal sensory axon terminals during postembryonic development with substantial retardation of growth of dendritic processes and spines and by alterations in physiological response properties. We have shown that these changes coincide with a marked decrease in protein synthetic capacity within the dendrites and somata of deafferented giant interneurons (Meyer and Edwards, 1982). These findings suggested that the presence of afferent terminals might serve to regulate transneuronally the level of protein metabolism within giant interneurons during postembryonic development. Thus, neuronal growth or stability might be influenced in proportion to degree of afferent innervation.

The synthesis and turnover of macromolecules important in neuronal function might also be specifically influenced by metabolic cues provided by presynaptic terminals in the cricket CNS. Nowhere would these effects be expected to be more pronounced than on the cell surface of target interneuron dendrites, most especially in regions where cercal afferents synapse with giant interneurons. We have therefore focused on the effect of deafferentation on the metabolism of macromolecules implicated in synaptic transmission in the cercal sensory-giant interneuron pathway.

Excitatory transmission across sensory pathways in most arthropods is mediated by ACh (Callec, 1974; Gerschenfeld, 1973). In orthopteroid insects, including crickets, transmission in the cercal sensory-giant interneuron pathway likewise involves cholinergic mechanisms, which have been characterized physiologically and pharmacologically (Harrow et al., 1982; Meyer and Reddy, 1985). Recently, we have identified and characterized in detail putative nicotinic and muscarinic $\mathrm{ACh}$ receptors (AChRs) in the terminal ganglion of Acheta (Meyer and Edwards, 1980; Meyer and Reddy, 1985). Specific binding sites of high affinity for both nicotinic and muscarinic ligands are present in high concentrations in the ganglion and, in particular, the nicotinic sites have been localized within the cercal sensorygiant interneuron pathway, where they appear to function as synaptic AChRs.

In this paper we describe the effects of cercal deafferentation on the levels of three specific cholinergic markers in the terminal ganglion: nicotinic and muscarinic binding sites and the enzyme acetylcholinesterase (AChE; E.C.3.1.1.7). We show that all of these macromolecules are markedly influenced by the loss of cercal afferent contacts.

Some of the results have been presented in part elsewhere (Edwards and Meyer, 1985; Meyer et al., 1983).

\section{Materials and Methods}

\section{Deafferentation}

Procedures for rearing, maintaining, and deafferentating crickets by cercectomy are described in detail elsewhere (Edwards and Palka, 1974; Meyer and Edwards, 1982; Palka and Edwards, 1974). Briefly, deafferentation was achieved by removing one or both of the paired cercal 
appendages (Fig. 1 $A$ ) either immediately after hatching (for chronic deafferentation through postembryonic development) or for varying durations in adult animals (short-term deafferentation). At the appropriate time, terminal ganglia (TG) were surgically removed for AChR and $\mathrm{AChE}$ assays or for localization of enzyme and binding sites in frozen sections of TG.

For examination of degenerating cercal nerve axons and terminals under phase contrast and at the ultrastructural level, ganglia were fixed in situ for $1-2 \mathrm{hr}$ at $22^{\circ} \mathrm{C}$ with $2 \%$ paraformaldehyde- $0.5 \%$ glutaraldehyde in Millonig's phosphate buffer. Following fixation, tissue was removed from the animal and prepared as described elsewhere (Edwards and Chen, 1979).

\section{Preparation of tissues for binding assays}

TG were removed from anesthetized adult female animals and were placed in ice-cold assay buffer [HEPES-buffered Levine saline (Levine, 1966), pH 7.4 (HBLS): $\mathrm{NaCl}, 183 \mathrm{~mm} ; \mathrm{KCl}, 3.0 \mathrm{~mm} ; \mathrm{CaCl}_{2}, 1.5 \mathrm{~mm}$ glucose, $57 \mathrm{~mm}$; $\mathrm{Na}_{2} \mathrm{HPO}_{4}, 0.43 \mathrm{~mm}$; $\mathrm{NaH}_{2} \mathrm{PO}_{4}, 0.18 \mathrm{~mm}$; HEPES, 10 $\mathrm{mM}$. Pooled TG from control and deafferented groups were homogenized in HBLS on ice in a glass-glass microhomogenizer and the crude, or centrifuged and rinsed, TG homogenate was diluted with HBLS to an assay concentration of 10-20 TG equivalents $/ \mathrm{ml}$ (final dilution in reaction tubes of 1-2 TG/assay volume; $20-50 \mu \mathrm{g}$ protein)

\section{Assay for muscarinic binding sites}

Methods developed for assaying the equilibrium binding of the specific muscarinic antagonist ligand ${ }^{3} \mathrm{H}-1$-quinuclidinyl benzilate $\left({ }^{3} \mathrm{H}-\mathrm{QNB}\right)$ to homogenates of Acheta TG preparations are reported in detail elsewhere (Meyer and Reddy, 1985). Briefly, specific binding of ${ }^{3} \mathrm{H}-\mathrm{QNB}$ to putative muscarinic AChRs in TG homogenates prepared from both pooled control and deafferented TG was assayed using a modification of the filter binding method of Yamamura and Snyder (1974). Reactions were carried out in duplicate for $90-120 \mathrm{~min}$ at $22^{\circ} \mathrm{C}$ to achieve binding equilibrium and were terminated by rapid addition of $5 \mathrm{ml}$ ice-cold rinsing buffer $\left(50 \mathrm{mM} \mathrm{NaH}_{2} \mathrm{PO}_{4}, \mathrm{pH} 7.4\right)$ to the reaction tubes followed by rapid vacuum filtration and three successive $5 \mathrm{ml}$ rinses of the homogenates on filter disks. Nonspecific binding was determined in the presence of $10^{-5} \mathrm{M}$ atropine sulfate.

For isotherm experiments, reactions were performed using a broad range of ${ }^{3} \mathrm{H}-\mathrm{QNB}$ concentrations (e.g., $0.5-40 \mathrm{nM}$ ), including not less than five ligand concentrations. Values for maximal concentration of binding sites $\left(B_{\max }\right)$ and apparent equilibrium binding constant $\left(K_{\mathrm{DapD}}\right)$ were calculated by Scatchard (1949) analysis of the binding isotherm data. Only best-fit Scatchard lines with a correlation coefficient of 0.9 or above were accepted for use in obtaining binding parameters, and each experiment was performed at least twice. Protein concentration was determined in quadruplicate samples by a modification of the method of Lowry et al. (1951). For single concentration saturation binding experiments to determine approximate $B_{\max }$ values, ${ }^{3} \mathrm{H}-\mathrm{QNB}$ concentration was set at $40 \mathrm{~nm}$ and quintuplicate samples were analyzed.

\section{Assay for nicotinic binding sites}

Methods for characterizing the binding of the highly specific nicotinic ligand ${ }^{125} \mathrm{I}-\alpha$-bungarotoxin ( ${ }^{125} \mathrm{I}-\alpha \mathrm{BGT}$ ) to $\mathrm{TG}$ homogenate preparations are described elsewhere (Meyer and Reddy, 1985). As for the ${ }^{3} \mathrm{H}-\mathrm{QNB}$ studies, equilibrium binding experiments were carried out using duplicate samples, and all experiments were conducted at least twice. For each filter binding experiment comparing specific binding of ${ }^{125} \mathrm{I}-\alpha \mathrm{BGT}$ in control and deafferented TG homogenate preparations, a range of at least five ligand concentrations was used. Values for $B_{\max }$ and $K_{\text {Dapp }}$ were derived from best-fit (correlation coefficient $\geq 0.9$ ) Scatchard slopes. Following protein determinations, density values for both ligands were expressed as fmoles of specific binding sites per milligram of TG protein.

\section{Assay for AChE content in $T G$}

The activity of ganglionic AChE was estimated by the colorimetric method of Ellman et al. (1961), which uses acetylthiocholine iodide as the substrate. The levels of nonspecific cholinesterase (pseudocholinesterase) present throughout insect tissue were similarly estimated, except that butyrylthiocholine was used as the substrate. Briefly, $50 \mu \mathrm{l}$ aliquots of $T G$ homogenates were incubated in assay medium containing the appropriate substrate for $60 \mathrm{~min}$ at $22^{\circ} \mathrm{C}$. Esterase activities were expressed per milligram of TG protein, and all determinations were carried out in triplicate.
Autoradiographic localization of ${ }^{12} I-\alpha B G T$ binding sites and histochemical localization of $A C h E$

TG taken from control and unilatcrally ccrccetomized crickets were stored briefly in ice-cold HBLS, fixed in neutral buffered $4 \%$ paraformaldehyde, rinsed, embedded in O.C.T. (Lab-Tek) freezing medium, and rapidly frozen in liquid nitrogen-cooled isopentane. Frozen $6 \mu \mathrm{m}$ horizontal sections were collected on gelatinized slides and then used for either ${ }^{125}$ I- $\alpha$ BGT autoradiographic localization (details in Meyer and Reddy, 1985) or AChE histochemistry. For either technique, only bilaterally symmetrical sections through the region of the cercal glomerular neuropil were selected for comparative analysis of AChR or AChE distribution and density.

Staining for AChE was by the method of Karnovsky and Roots (1964). As controls, staining for nonspecific cholinesterase and for AChE in the presence of $10^{-3} \mathrm{M}$ eserine was carried out in parallel with AChE samples. For toxin labeling studies, sections were incubated for $120 \mathrm{~min}$ with 20 nм ${ }^{125} \mathrm{I}-\alpha \mathrm{BGT}$; nonspecific binding was determined by the addition of $10^{-4} \mathrm{M}$ nicotine to the preincubation and incubation media. Preparation for autoradiography was as described in Meyer and Reddy (1985).

\section{Supplies}

${ }^{3} \mathrm{H}-\mathrm{QNB}(\geq 30 \mathrm{Ci} / \mathrm{mmol})$ and ${ }^{125} \mathrm{I}-\alpha \mathrm{BCT}(\geq 200 \mathrm{Ci} / \mathrm{mmol})$ were obtained from New England Nuclear. All drugs and substrates were supplied by either Sigma or Aldrich Chemical Co. All other compounds used were obtained from commercial sources and were of reagent grade. NTB-2 emulsion for autoradiography was from Kodak.

\section{Results}

\section{Morphological correlates of deafferentation}

The cell bodies of arthropod sensory neurons are situated in the epidermis (Fig. 1 $A$ ); their axons and central terminals degenerate rapidly after the amputation of appendages (Lamparter et al., 1969). Removal of abdominal cerci in Acheta maintained at $22^{\circ} \mathrm{C}$ causes detectable ultrastructural changes in axons and terminals within $1-3 \mathrm{hr}$

The first signs of change appear in axons, which begin to collapse and condense (Fig. $1 B$ ), leaving increased extracellular spaces. Within the ganglionic neuropil, terminal and subterminal regions of sensory axons show swollen mitochondria and a pronounced increase in fine-textured osmiophilia in axoplasm by $3 \mathrm{hr}$ (Fig. $1 C, D$ ). By $6 \mathrm{hr}$, terminals approach a plateau of increased osmiophilia, mitochondria are disrupted, and clear vacuolar zones appear.

Degenerated axons are clearly visible during the subsequent 1-2 d (J. S. Edwards, unpublished observations). Multivesicular bodies and membrane accumulations increase in prominence during this period and are thereafter dispersed, presumably by glial action. For the present purposes, these observations indicate that normal interactions between the majority of afferent axons and their target interneurons begin to decline within an hour of cercal amputation and cease within about a day.

\section{Effects of deafferentation on TG muscarinic binding sites}

Adult fermale TG contain a very high density (30-40 fmol/ ganglion) of sites that specifically bind the muscarinic antagonist ${ }^{3} \mathrm{H}-\mathrm{QNB}$ with high affinity (Meyer and Reddy, 1985). Although only found in the CNS, the distribution of the putative muscarinic AChRs throughout the CNS has not yet been determined.

Despite the rapid degeneration of cercal sensory axons and terminals following cercectomy of adult animals, the binding site density $\left(B_{\max }\right)$ values for putative muscarinic AChRs, as calculated from Scatchard analysis of binding isotherm data, are not appreciably decreased in deafferented TG, even after 2 weeks (Figs. $2 A, 3 A$ ). By this time, only a slight $(12 \%)$ decrease in $B_{\max }$ is seen. On the other hand, during at least the initial 9$10 \mathrm{~d}$ following deafferentation, modest but consistent increases in the concentrations of ${ }^{3} \mathrm{H}-\mathrm{QNB}$ sites are detected. Peak mean 

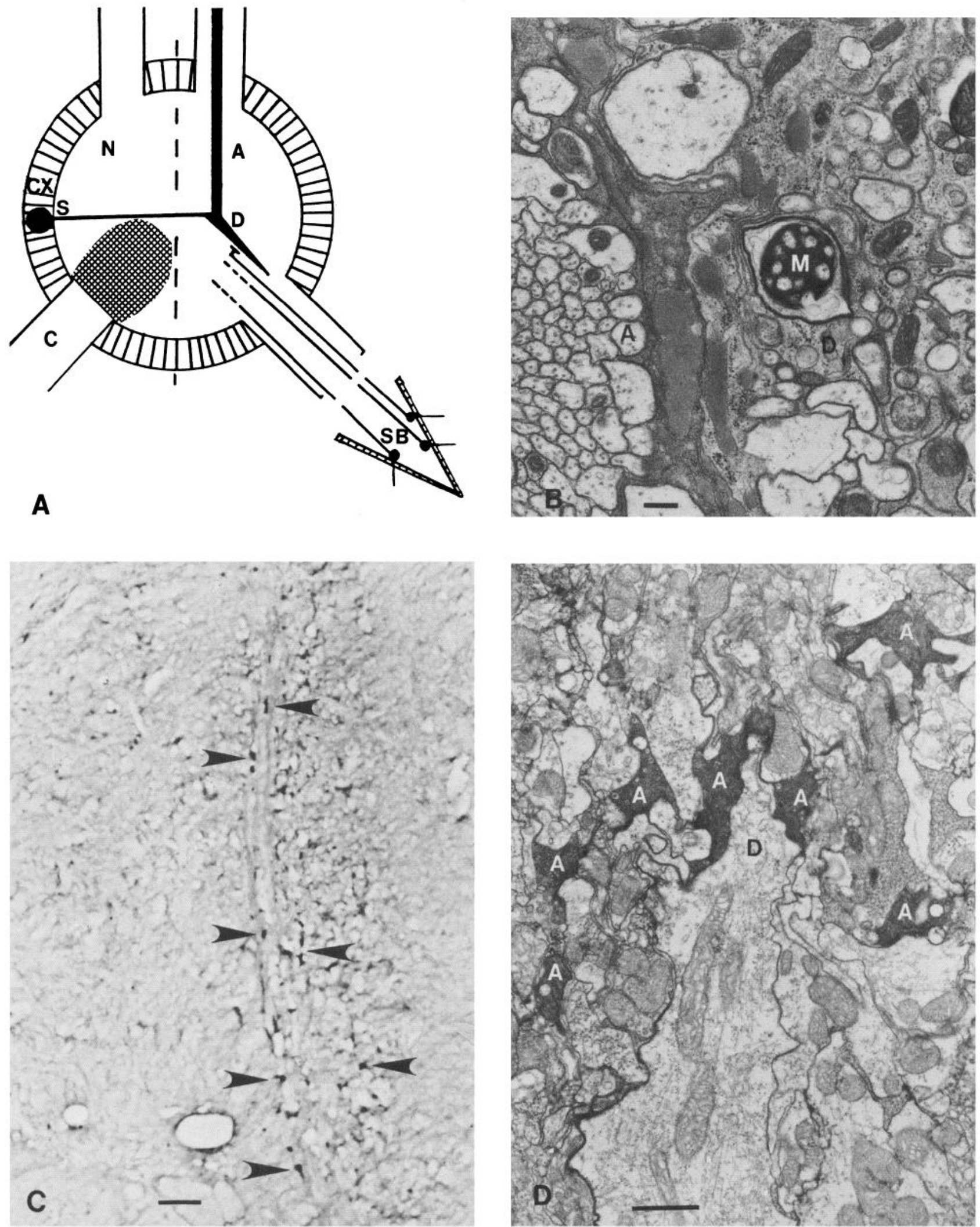

Figure 1. A, Schematic horizontal section of the terminal abdominal ganglion. Cortex $(c x)$, occupied by cell bodies of motor and interneurons, surrounds neuropil $(N)$. Cercal sensory nerves $(C)$ enter the ganglion at posterior-lateral angles. Sensory cell bodies $(S B)$ of cercal sensilla $($ lower right) send axonal projections to giant dendrites $(D)$ and other sites (dashed lines). The majority of synaptic contacts with giant interneuron dendrites occur within cercal glomerulus (hatched zone lower left quadrant). One typical giant interneuron arises from soma (s) in cortex and extends a dendrite $(D)$ into contralateral neuropil, while its axon $(A)$ leaves the ganglion within one of the paired ventral connectives. $B$, Segment of cercal sensory nerve in transverse section; transmission electron micrograph, $3 \mathrm{hr}$ after cercal amputation. Normal sensory axons $(A)$ from extracercal sources occupy left middle and lower areas. Extensive areas of degenerating cercal sensory axons $(D)$ interspersed with glia and extracellular material 

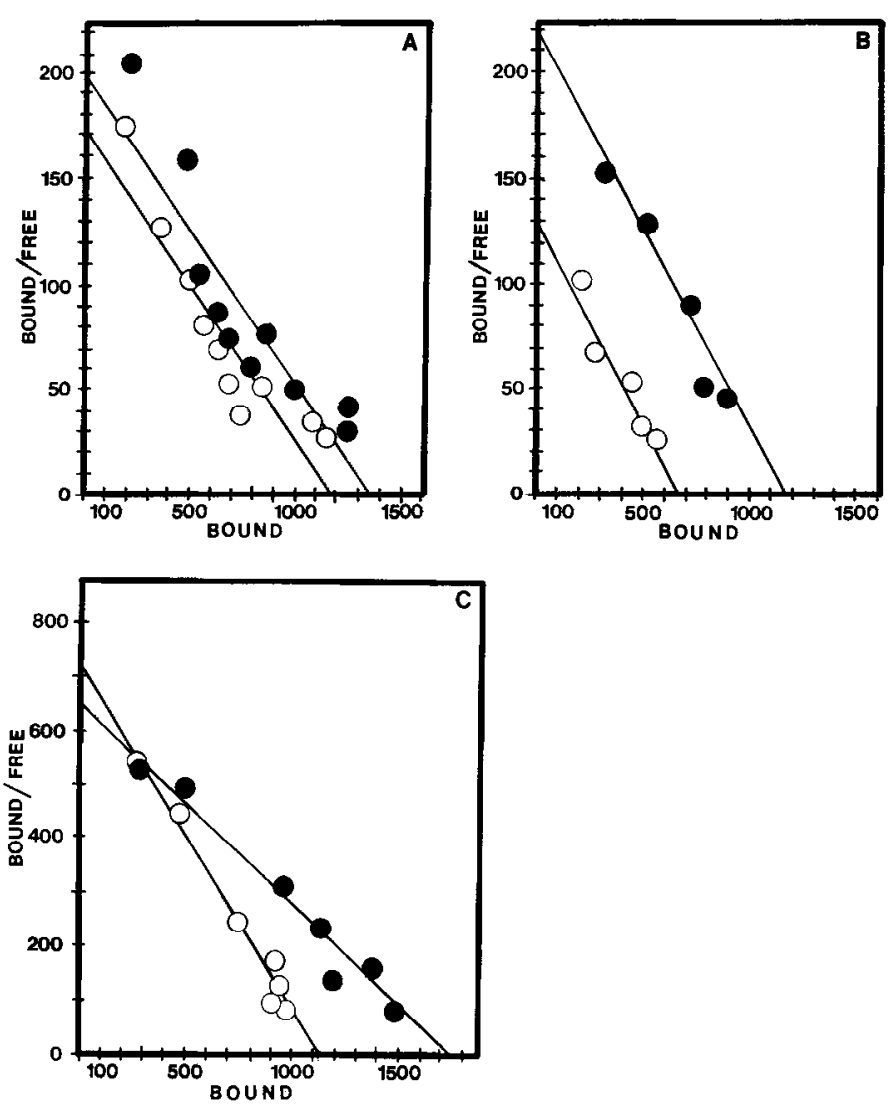

Figure 2. Analysis of labeled ligand binding to TG cholinergic sites following deafferentation. Pooled adult TG from parallel reared control $(\bullet)$ and bilaterally deafferented $(O)$ groups were prepared for binding assays using either ${ }^{3} \mathrm{H}-\mathrm{QNB}(A, B)$ or ${ }^{125} \mathrm{I}-\alpha \mathrm{BGT}(C)$ to characterize putative muscarinic and nicotinic AChRs, respectively (see Methods).

Data from equilibrium binding isotherms were plotted by the method of Scatchard (1949) to determine maximal binding site density $\left(B_{\max }\right)$, indicated graphically by point at which best-fit regression line intersects abscissa (units in $\mathrm{fmol} / \mathrm{mg}$ protein). Slope represents negative reciprocal of apparent dissociation constant $\left(K_{\text {Dapp }}\right)$, a measure of binding site affinity.

Comparison of $15 \mathrm{~d}$ deafferented adult group with paired control TG group $(A)$ shows only slight $(10 \%)$ reduction in density of muscarinic sites. Chronic deafferentation sustained throughout postembryonic development $(B)$ induces a marked $(41 \%)$ loss of ${ }^{3} \mathrm{H}-\mathrm{O} N \mathrm{~B}$ binding sites. For ${ }^{125} I-\alpha B G T$ sites $(C)$, note that substantial loss of putative nicotinic AChRs is seen $15 \mathrm{~d}$ following deafferentation of adult animals. Decrease in $B_{\max }$ shown here is accompanied by shift in binding site affinity $\left(K_{\text {Dapp }}\right)$, as reflected by the disparity in the slopes of the regression lines. Data are representative of experimental values obtained from multiple assays.

elevations in $B_{\max }$ of close to $30 \%$ occurred at 1 week, and none of the elevations was accompanied by detectable alterations in the affinity of the binding sites for ligand. Thus, in adult animals, the initial response to deafferentation is an increased synthesis or expression of muscarinic binding sites, followed by a gradual decrease to a level slightly below the $B_{\max }$ values for paired control TG.
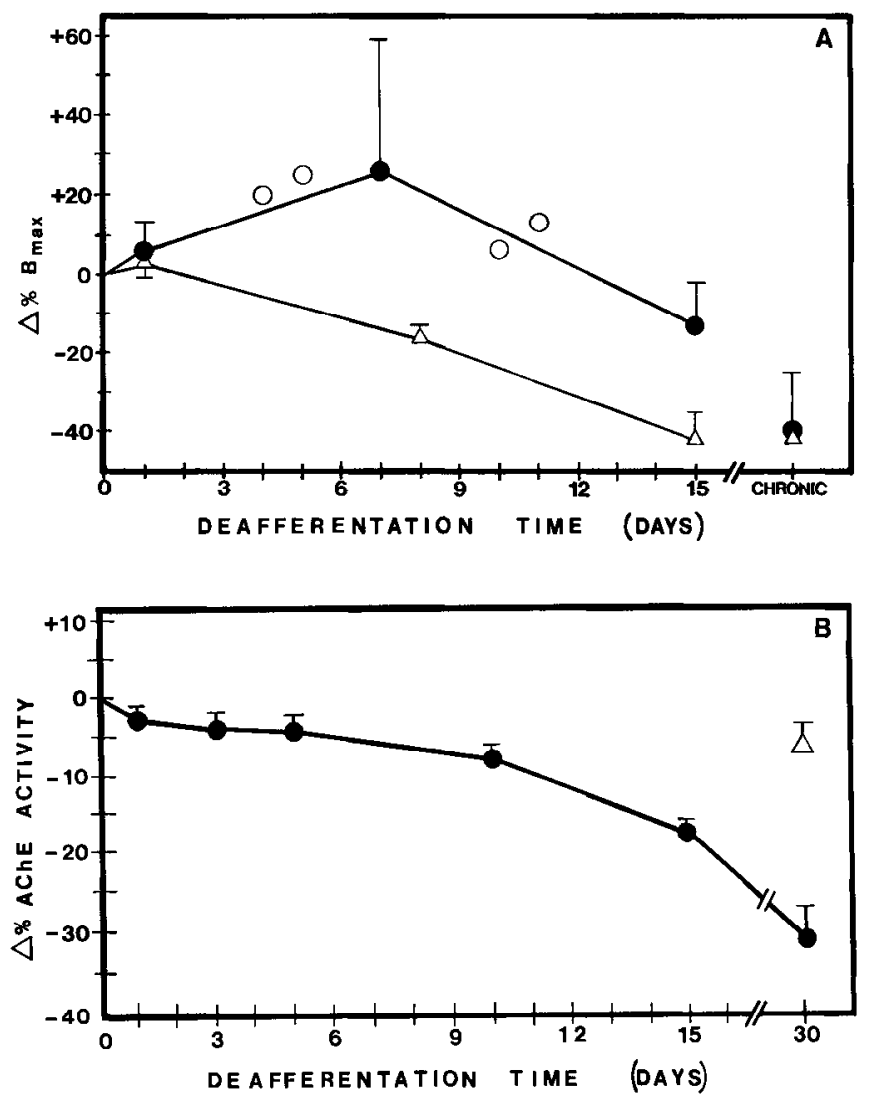

Figure 3. Effects of deafferentation time on concentrations of TG muscarinic and nicotinic binding sites and $\mathrm{AChE}$ activity. $A$, Values for changes in maximal binding site densities between paired control and deafferented groups $\left(\Delta \% B_{\mathrm{max}}\right)$ were derived from Scatchard analysis of equilibrium isotherms for binding of either ${ }^{3} \mathrm{H}-\mathrm{QNB}(\Theta)$ or ${ }^{125}{ }^{25}-\alpha \mathrm{BGT}$ $(\triangle)$ to TG homogenates, as described in text. Each point on the composite graph represents the mean change ( \pm SEM) obtained from at least two separate kinetic experiments, except for chronic deafferentation experiment with ${ }^{125} \mathrm{I}-\alpha \mathrm{BGT}$, which was performed once. For some time points $(O)$, approximate $B_{\max }$ values were calculated by incubation of TG groups with a single saturating ( $40 \mathrm{nM}$ ) concentration of ${ }^{3} \mathrm{H}-\mathrm{QNB}$; these values represent data taken from individual experiments performed in quintuplicate. $B$, Changes in AChE activity $(O)$ between paired control and deafferented groups of TG were obtained from colorimetric assay data (see text). Values were expressed in terms of enzyme units per $\mathrm{mg}$ TG protein. All points on the composite graph represent mean $( \pm$ SD) differences between groups from at least two separate determinations. The activity of nonspecific cholinesterase $(\Delta)$ is not appreciably altered after $30 \mathrm{~d}$ deafferentation, compared with specific AChE activity.

The results from experiments in which deafferentation is initiated at hatching and is sustained throughout postembryonic development differ markedly from those of deafferentation in adult animals. A $40 \%$ decrease in binding site concentration is measured by Scatchard analysis of the equilibrium isotherms (Figs. $2 B, 3 A$ ), and this reduction in $B_{\max }$ is not associated with detectable changes in binding-site affinity $\left(K_{\mathrm{D}}\right)$ (Fig. $2 B$ ), thus reflecting a true loss of putative muscarinic $A C h R s$ from the CNS of deafferented animals. Although loss of neuropil volume

$\longleftarrow$

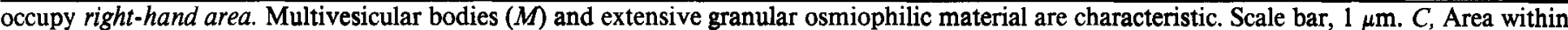

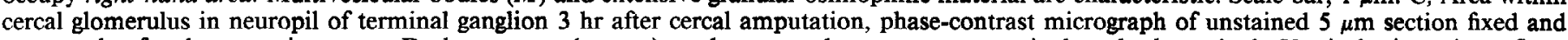

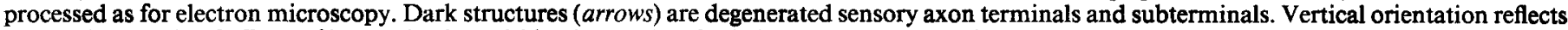

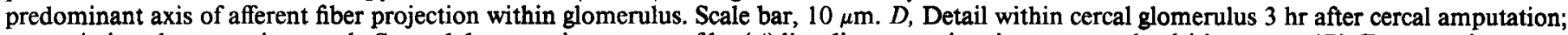

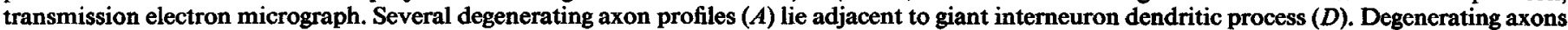
are intensely osmiophilic and, in some cases, vacuolated. Elsewhere, clear profiles are predominantly fine dendritic branches. Scale bar, $1 \mu \mathrm{m}$. 

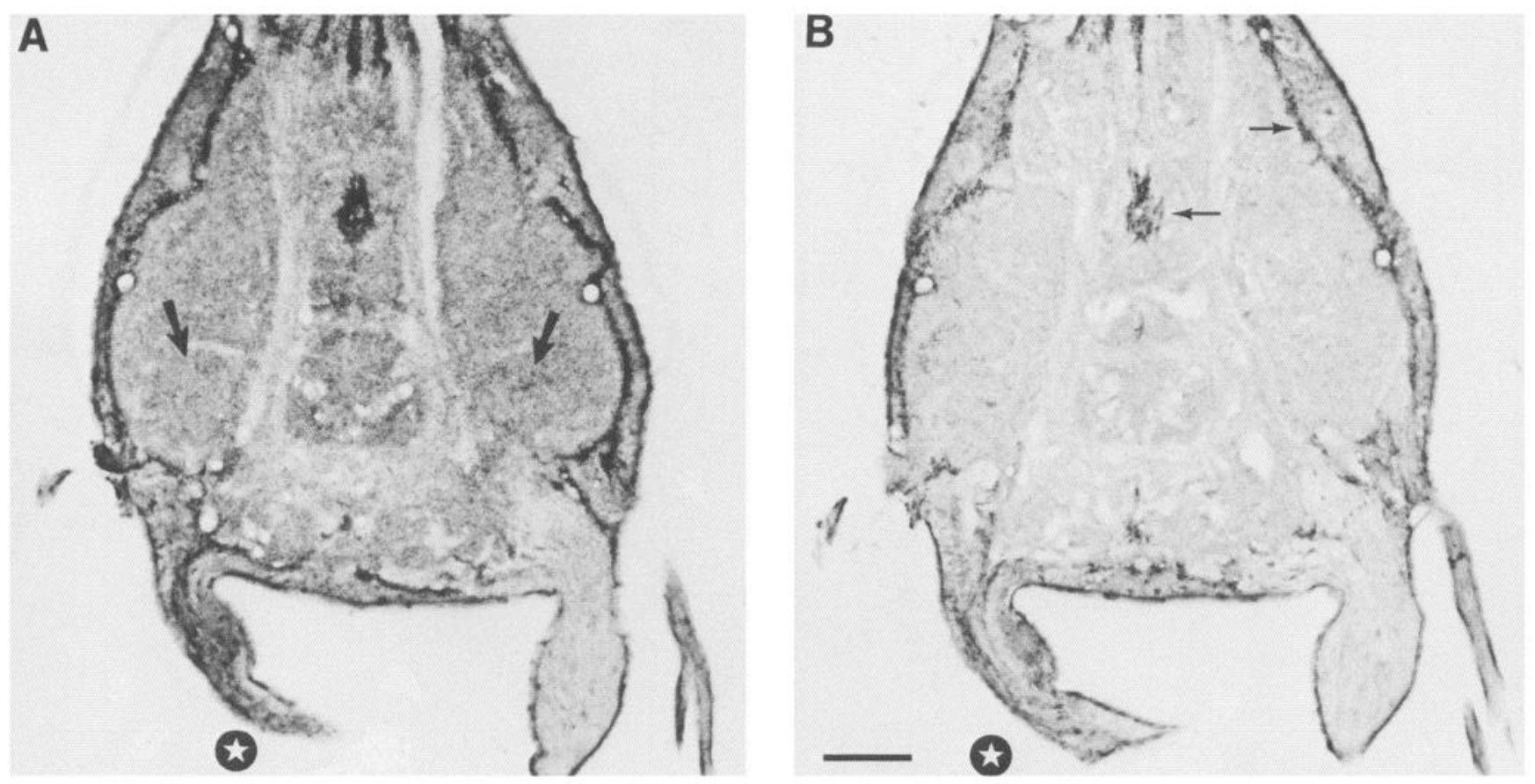

Figure 4. Autoradiographic localization of labeled toxin binding in unilaterally deafferented TG. Adult animals were cercectomized on one side (star) $15 \mathrm{~d}$ prior to preparation of frozen sections of TG for incubation in ${ }^{125} \mathrm{I}-\alpha \mathrm{BGT}$ and autoradiography (see text). Total distribution of toxin binding sites $(A)$ shows substantial labeling throughout ganglion, with highest specific grain densities in cercal glomerular neuropil and adjacent areas (arrows). Comparison of binding densities within these regions demonstrates moderate decrease (i.e., $\geq 10 \%$ by random sampling with microscopic photometric scanning) in posterior neuropil on deafferented side. This trend is representative of results obtained with four other ganglia. Note degeneration of cercal sensory nerve on experimental side of TG. Adjacent section $(B)$, treated with $10^{-4} M$ nicotine, reveals nonspecific residual binding of labeled toxin to glial areas in cortical rind and dorsal pit (small arrows). Nicotine displaces essentially all label from neuropil, which suggests that it contains high density of specific putative nicotinic AChRs. Scale bar, $100 \mu \mathrm{m}$.

and protein content may be significant during chronic deafferentation ( $30 \%$; Meyer and Edwards, 1982), these changes are accounted for in measurements of specific activity of the binding, which are always adjusted for total ganglionic protein.

In order to determine whether the loss of muscarinic sites induced by chronic deafferentation was permanent or could be reversed by subsequent reinnervation by cercal afferents, cerci were permitted to regenerate on the following schedule: From the seventh postembryonic instar to adulthood, a bilaterally cercectomized group was allowed to regenerate cerci (and afferent projections). Approximate $B_{\max }$ values for this group of ganglia were then compared with those of groups of TG taken from control and continually deafferented animals raised in parallel. Results (Table 1) indicate that the partial reinnervation of TG central elements by new cercal afferents is associated with a return of binding site concentrations toward control values.

\section{Table 1. Reinnervation reverses loss of TG ${ }^{3} \mathrm{H}-\mathrm{QNB}$ binding sites}

\begin{tabular}{lcl} 
Group & $\begin{array}{l}\text { Specific } \\
{ }^{3} \mathrm{H}-\mathrm{QNB} \text { bound } \\
(\mathrm{fmol} / \mathrm{mg} \text { protein) }\end{array}$ & $\begin{array}{l}\text { Difference } \\
(\%)\end{array}$ \\
\hline Control & $1276 \pm 206^{b}$ & - \\
Continuous deafferentation & $893 \pm 75$ & 30.0 \\
Seventh instar regeneration & $1076 \pm 193$ & 15.6
\end{tabular}

approximate $B_{\max }$ values obtained by incubation of pooled TG homogenates for $120 \mathrm{~min}$ with $40 \mathrm{nM}{ }^{3} \mathrm{H}-\mathrm{QNB}$.

${ }^{b}$ Mean ( $\left.\pm \mathrm{SD}\right)$ from quintuplicate samples.

c Only animals that had regenerated cerci to at least $50 \%$ of control cercal appendage length bilaterally were selected $(n=9)$.
Thus, loss of putative muscarinic AChRs is reversible, and their recovery depends on restoration of afferent projections to the CNS.

\section{Effects of deafferentation on TG nicotinic binding sites}

Putative nicotinic AChRs in the TG, a portion of which are known to occur in the cercal sensory-giant interneuron pathway of Acheta (Meyer and Reddy, 1985), respond differently to deafferentation than muscarinic sites (Fig. $3 A$ ). By about 1 week, slight but characteristic decreases in $B_{\max }$ values were detected. Within $15 \mathrm{~d}$ following cercectomy, the loss of ganglionic binding sites was substantial ( $\sim 40 \%$; Fig. $2 C$ ). The magnitude of the decreases in binding seen at 2 weeks in deafferented adult animals was comparable to the maximal reductions in $B_{\max }$ values found for chronically deafferented TG in both ${ }^{3} \mathrm{H}-\mathrm{QNB}$ and ${ }^{125} \mathrm{I}-$ $\alpha \mathrm{BGT}$ assays (Figs. $2, B$ and $C ; 3 A$ ). The decreases in $B_{\max }$ values for labeled toxin, calculated by kinetic analysis of binding isotherms, were accompanied by notable changes in the apparent affinity of the ligand for its receptor $\left(\mathrm{K}_{\text {Dapp }}\right)$, as reflected by the unequal slopes observed in the Scatchard plots (Fig. 2C). These findings also contrast with those for ${ }^{3} \mathrm{H}-\mathrm{QNB}$ binding and indicate that more complex kinetic alterations in nicotinic binding site properties may occur following deafferentation, such as receptor uncoupling or conformational changes, in parallel with removal of the sites.

We have recently described the distribution of bound ${ }^{125} \mathrm{I}-$ $\alpha$ BGT in frozen sections of TG (Meyer and Reddy, 1985) using autoradiography. Increased levels of specific labeling were observed in neuropilar areas of the TG; the highest levels of binding were associated with cercal glomerular neuropil and identifiable dendrite processes of giant interneurons, thereby associating toxin binding with presumptive synaptic areas in the CNS. 
In TG from animals that had been unilaterally cercectomized $15 \mathrm{~d}$ prior to preparation for autoradiography, comparisons between control and deafferented sides of the ganglion (Fig. 4A) showed slight but consistent differences in grain densities, which correspond to the concentrations of putative nicotinic AChRs. Especially in cercal glomerular regions of TG neuropil, but also in adjacent areas, grain densities were always reduced (as judged by double-blind observation) over deafferented regions. No differences were apparent, however, in the distribution of nonspecific binding of labeled toxin over neuronal, glial, or extracellular elements in these regions (Fig. $4 B$ ). Since no significant changes in the nonspecific tissue distribution of label were induced by deafferentation, we conclude that the small differences we observed must represent actual changes in AChR densities. These results thus tend to substantiate those derived from in vitro binding assays.

\section{Effects of deafferentation on AChE activity in $T G$}

The enzyme AChE occurs throughout the insect nervous system and is found predominantly in pre- and postsynaptic neuronal elements, although it may also be present in glial cells (Smith and Treherne, 1965; Wigglesworth, 1958). Undoubtedly AChE participates in cholinergic synaptic transmission in insects, including within the cercal sensory-giant interneuron pathway of orthopteroids (Harrow and Sattelle, 1983; Roeder et al., 1947; M. R. Meyer, unpublished observations).

AChE activity gradually decreases within days following removal of cercal appendages from adult animals (Fig. $3 B$ ), with a less than $10 \%$ reduction observed after about $10 \mathrm{~d}$. At later times, reductions in specific enzyme activities become more pronounced, so that by $30 \mathrm{~d}$ following deafferentation, levels are depressed by more than $30 \%$ (per mg TG protein). Thus, in adult animals, the rate of AChE activity decrease appears intermediate between those for reduction in binding site densities for putative muscarinic and nicotinic AChRs. The declines in AChE activity appear to be specific and related to neuronal elements, since the activity of nonspecific cholinesterase is not appreciably altered after deafferentation (Fig. $3 B$ ).

Histochemical staining for AChE activity (Fig. 5) reveals intense bilateral reactivity in posterior regions of neuropil in control TG, corresponding to the ovate peripheral boundaries of the cercal glomerulus (Fig. $5 A$ ). Somc staining was also associated with cercal afferent projections, probably representing a presynaptic contribution to total ganglionic AChE content

Comparison of control and deafferented regions in neuropil in frozen sections of $\mathrm{TG}$ from unilaterally deafferented adult animals revealed that a substantial loss of AChE occurred within $3 \mathrm{~d}$ (Fig. $5 B$ ) of cercectomy and that near-maximal reduction in enzyme activity was reached within a week (Fig. $5 C$ ). By day 15 , little or no observable AChE activity was detectable over deafferented regions of cercal glomerular neuropil (data not shown). These results indicate that loss of cercal afferents is associated with a rapid and pronounced reduction in ganglionic AChE activity and that the most striking changes are found in regions of neuropil comprising the cercal glomerulus. This trend correlates with similar findings for loss of $\alpha \mathrm{BGT}$ binding sites, and decreases in AChE seem to follow a time course somewhat similar to that for putative nicotinic AChRs.

\section{Discussion}

The concentrations of three macromolecules in the terminal ganglion of Acheta that are presumed to be associated with cholinergic transmission in an identifiable neural pathway are altered following cercal deafferentation. These findings for specific proteins in the CNS reinforce results from previous studies demonstrating the pronounced effects of loss of afferent terminals on target interneuron dendritic growth (Murphey and Levine, 1980; Murphey et al., 1975) and on both ganglionic and intraneuronal protein synthesis (Meyer and Edwards, 1982). The general view that now emerges is thus that the growth, protein metabolism, and concentrations of likely cell-surface components of insect central neurons are all influenced by the state of afferent innervation and, most importantly, that these influences may be active not only during postembryonic development, but in the adult as well.

At the molecular level, as a consequence of the rapid loss of afferent terminals within hours of cercectomy, measurable changes in the concentrations of ganglionic muscarinic and nicotinic cholinergic sites and AChE activity are detected within several days in deafferented adult animals. Maximal losses of toxin binding sites and $\mathrm{AChE}$ are found within several weeks. In particular, the degree of reduction of $B_{\max }$ for ${ }^{125} I-\alpha B G T$ after short-term deafferentation matches that seen following sustained deafferentation throughout postembryonic development.

The response of muscarinic sites to deafferentation, as measured by specific ${ }^{3} \mathrm{H}-\mathrm{QNB}$ binding, is distinct from that for nicotinic sites and AChE. Maximal reductions in muscarinic binding site concentration are observed only following chronic deafferentation, when the decrease in $B_{\max }(\sim 40 \%)$ parallels that for the loss of nicotinic sites. On the contrary, after short-term deafferentation, a transient increase in $B_{\max }$ is first seen for putative muscarinic AChRs.

AChE activity in the TG appears to be significantly reduced following short-term deafferentation in adult animals, although more slowly and to a lesser degree than for reductions in toxin binding. Therefore, although the properties of all three cholinergic markers clearly show evidence for regulation by the periphery, they also show independent and characteristic responses to deafferentation.

\section{Regulation of putative muscarinic AChRs}

Despite the fact that specific ${ }^{3} \mathrm{H}-\mathrm{QNB}$ binding sites are present at extremely high density in the Acheta TG and have been pharmacologically characterized in the cricket and other insects (Ben-Barak and Dudai, 1977; Jones and Sumikawa, 1981; Meyer and Edwards, 1980; Meyer and Reddy, 1985; Shaker and Eldefrawi, 1981), little is known of their localization in the CNS, much less their possible function. Our results from deafferentation experiments in the cricket provide an initial insight into the distribution of putative muscarinic AChRs in the insect CNS. Since TG binding-site densities are measurably altered following either short- or long-term deafferentation, we can infer that at least a portion of the sites must reside somewhere within the network that comprises the cercal sensory-giant interneuron pathway. Further, since we detect a close to $30 \%$ increase in $B_{\max }$ subsequent to the loss of a large complement of afferent terminals following cercectomy, a presynaptic locus for putative muscarinic AChRs must be ruled out. On the other hand, based on our inability, in initial attempts, to detect unequivocal physiological effects of muscarinic agents on pathway transmission, we have no information on a functional postsynaptic site distribution. At the present time, we can only conjecture on the disposition of the muscarinic sites. Possibilities include (1) extrasynaptic loci (e.g., on neuronal somata, glia, etc.); (2) location on interneurons or motoneurons in the CNS far removed (i.e., polysynaptically) from direct contacts between cercal afferents and giant interneurons processes; and (3) the existence of putative muscarinic AChRs in portions of the CNS directly innervated by cercal afferents but that evade physiological detection by extracellular recording criteria, which monitors only selective giant interneuron action potential volleys in the abdominal connectives (Meyer and Reddy, 1985; but see also Harrow et al., 1982).

In the vertebrates, central and peripheral muscarinic AChRs show a wide range of responses to denervation or deafferentation; marked increases, decreases, and no effect on receptor 

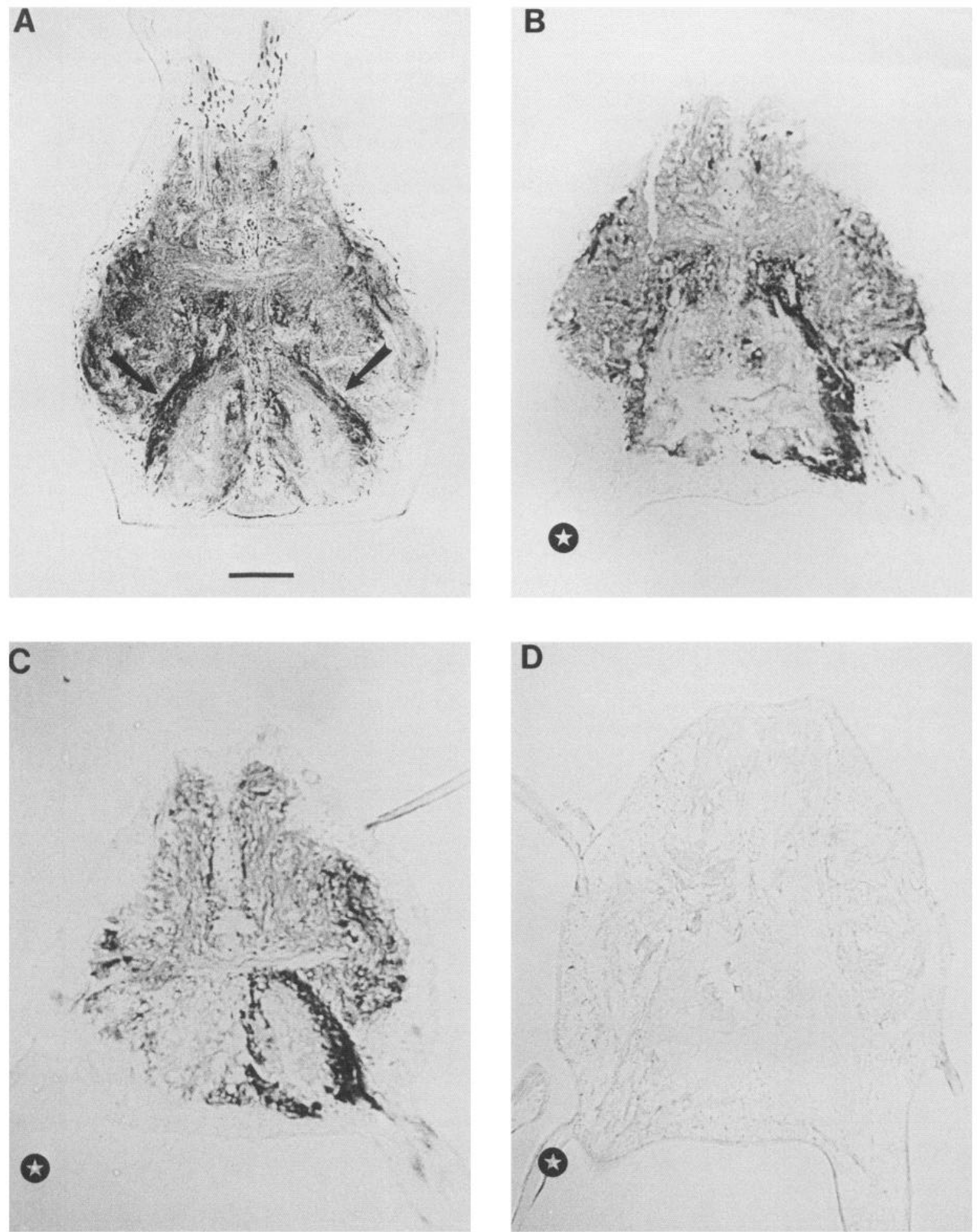

Figure 5. Histochemical localization of AChE activity in unilaterally deafferented TG. $A$, Control animal. AChE is distributed throughout ganglion but predominantly in neuropil. Note highest concentrations localized bilaterally in regions comprising cercal glomeruli (arrows). $B$, Significant loss of AChE activity is apparent within $3 \mathrm{~d}$ in cercal glomerular neuropil on deafferented side (star). $C$, Maximal loss occurs within $7 \mathrm{~d}$ of cercectomy. $D$, Generally light, diffuse appearance of nonspecific cholinesterase staining in ganglion. No difference in distribution of activity between control and deafferented (star) sides is observed $7 \mathrm{~d}$ following cercectomy. Scale bar, $100 \mu \mathrm{m}$.

concentrations have been observed (Ben-Barak and Dudai, 1980; McKinney and Coyle, 1982; Rotter et al., 1979; Taniguchi et al., 1983). Depending on the developmental stage at which deafferentation is carried out and its duration, TG muscarinic sites can respond with increases or decreases in concentration. This probably reflects inducible changes in the rate of receptor turnover (i.e., synthesis and degradation). Evidence for both receptor "up-" and "down-regulation" has been presented for a wide 
variety of neurotransmitter and hormone receptors, which, in some cases, may involve complex mechanisms whereby agonist occupancy influences receptor metabolism and turnover (Creese and Sibley, 1981; Davies and Lefkowitz, 1981). An alternative possibility for the observed transient increases in muscarinic binding site densities would involve the massive sprouting of noncercal cholinergic afferents into denervated regions of neuropil. Such processes might activate de novo synthesis and expression of receptor macromolecules; evidence for similar mechanisms has been demonstrated recently in the mammalian brain (Morrow et al., 1983).

Although agonist-dependent interactions or sprouting may occur during short-term deafferentation, the marked losses of binding sites observed after chronic deafferentation that correspond closely in magnitude to decreases in ganglionic protein synthesis reported after similar procedures (Meyer and Edwards, 1982) indicate that other factors, such as growth cues or trophic substances provided by afferent innervation, may also be important. That reinnervation by cercal afferents partially reverses the effects of long-term deafferentation on the concentration of muscarinic sites lends further support to this notion. Thus, receptor-site metabolism may be regulated by more than one process and in a complex, multifaceted fashion. In Acheta, nonetheless, it is evident that in both the developing and the adult CNS, innervation-dependent mechanisms play a part and are wide-ranging in their action on the metabolism of putative muscarinic AChRs.

\section{Regulation of putative nicotinic AChRs and $A C h E$}

Unlike muscarinic sites, there is substantial information on the location and function of putative nicotinic AChRs and AChE in the insect CNS, in which both macromolecules are thought to participate in excitatory cholinergic transmission between sensory neurons and specific interneurons (Callec, 1974; Harrow et al., 1982). This appears true for the cercal sensory-giant interneuron pathway of Acheta based on physiological, pharmacological, and histochemical criteria (Meyer and Reddy, 1985; M. R. Meyer, unpublished observations).

Most physiological evidence favors a postsynaptic localization for nicotinic AChRs in the insect CNS (Harrow et al., 1979), and this view is supported by autoradiographic data on the distribution of labeled toxin binding sites in cricket TG (Meyer and Reddy, 1985) and in other insects (Hildebrand et al., 1979; Schmidt-Nielsen et al., 1977). Although there is some recent evidence for the existence of extrasynaptic (e.g., perikaryal) insect nicotinic AChRs (Harrow and Sattelle, 1983; Lees et al., 1983), there is as yet no support for the existence of presynaptic loci for AChRs in insects. Our findings, then, for the rapid loss of TG nicotinic binding sites following cercal deafferentation are most likely to reflect the loss of postsynaptic sites, a major portion of which reside in synaptic neuropil and may represent functional AChRs. Evidence from autoradiographic analysis of specific ${ }^{125} \mathrm{I}-\alpha \mathrm{BGT}$ binding, which generally shows decreased labeling over deafferented cercal glomerular neuropil and adjacent regions, reinforces this likelihood. Our results, however, do not agree with findings for deafferented antennal lobes in the developing brain of the moth Manduca sexta, in which only slight reductions in toxin binding were reported (Hildebrand et al., 1979; Sanes et al., 1977).

AChE activity is substantially reduced in deafferented adult TG in a manner similar to putative nicotinic $\mathrm{AChRs}$, albeit over a longer time course. Since the distribution of $\mathrm{AChE}$ in the insect nervous system is widespread (Smith and Treherne, 1965; Wigglesworth, 1958), some of the decrease in AChE observed shortly after cercectomy may reflect the loss of enzyme stores situated in cercal axons and their terminals. It is unlikely, however, that a presynaptic complement could account wholly for the magnitude of the decreases measured, most especially at times after the majority of afferent terminals have degenerated (e.g., after about a week). These changes most probably reflect diminution of AChE in postsynaptic elements, including that which is likely to be associated with giant interneuron dendritic processes.

The alteration of concentrations of putative muscarinic and nicotinic AChRs and AChE in the TG following cercal deafferentation in both developing and adult Acheta strongly suggests that nerve-dependent regulatory mechanisms that may influence specific biochemical properties of central target neurons are in operation. These observations confirm and further define our previous results, which demonstrated a relationship between the presence of cercal afferents and the level of protein synthesis within giant interneuron dendrites during postembryonic development (Meyer and Reddy, 1985). Since similar processes operate in adult animals to influence the turnover of specific macromolecules, these cellular interactions may now be looked on as having as great an effect on determining the biochemical plasticity of neurons in the adult CNS as they do on regulating growth of central neurons during embryonic (Shankland et al., 1982) and postembryonic (Murphey et al., 1975) development.

At the vertebrate neuromuscular junction, the properties of both nicotinic AChRs and AChE appear to be regulated by neurotrophic factors associated with presynaptic terminals (Fambrough, 1979; Fernandez et al., 1979). Rather less is known about the transsynaptic modulation of the biochemical properties of peripheral and central neurons, but various molecular mechanisms have been implicated (see Berg, 1984, and Cotman and Nieto-Sampedro, 1984, for reviews). Thus far, however, similar trophic mechanisms have not been observed in insects, much less investigated in detail. In previous papers (Edwards and Meyer, 1985; Meyer and Edwards, 1982), we have speculated on mechanisms whereby transneuronal signals between peripheral neurons and their postsynaptic targets might serve to regulate nerve cell metabolism and growth. Our demonstration of innervation-dependent effects on identifiable macromolecules in the CNS now allows us to focus on interneuronal regulatory mechanisms that may operate both during ontogeny and maturity.

\section{References}

Ben-Barak, J., and Y. Dudai (1977) Muscarinic receptor in Drosophila melanogaster demonstrated by binding of ${ }^{3} \mathrm{H}$-quinuclidinyl benzilate. FEBS Lett. 81: 134-136.

Ben-Barak, J., and Y. Dudai (1980) Early septal lesion: Effect on the development of the cholinergic system in rat hippocampus. Brain Res. 185: 323-334.

Berg, D. K. (1984) New neuronal growth factors. Annu. Rev. Neurosci. 7: $149-170$.

Callec, J.-J. (1974) Synaptic transmission in the central nervous system of insects. In Insect Neurobiology, J. E. Treherne, ed., pp. 119-178, Elsevier/North Holland, Amsterdam.

Cotman, C. W., and M. Nieto-Sampedro (1984) Cell biology of synaptic plasticity. Science 225: 1287-1294.

Cowan, W. M. (1970) Anterograde and retrograde transeuronal degeneration in the central and peripheral nervous system. In Contemporary Research Methods in Neuroanatomy, W. J. H. Nauta and S. O. E. Ebbesson, eds., pp. 217-251, Springer-Verlag, New York.

Creese, I., and D. R. Sibley (1981) Receptor adaptations to centrally acting drugs. Annu. Rev. Pharmacol. Toxicol. 21: 357-391.

Davies, A. O., and R. J. Lefkowitz (1981) Regulation of adrenergic receptors. In Receptor Regulation, R. J. Lefkowitz, ed., pp. 83-121, Receptors and Recognition, Series B, Vol. 13, Chapman and Hall, New York.

Edwards, J. S., and S.-W. Chen (1979) Embryonic development of an insect sensory system, the abdominal cerci of Acheta domesticus. Roux's Arch. Dev. Biol. 186: 151-178.

Edwards, J. S., and M. R. Meyer (1985) Developmental interactions between neurons in insects. In Molecular Bases of Neural Development. G. M. Edelman and W. E. Gall, eds., pp. 317-339, Research Foundation, Plenum, New York. 
Edwards, J. S., and J. Palka (1974) The cerci and abdominal giant fibres of the house cricket Acheta domesticus. I. Anatomy and physiology of normal adults. Proc. R. Soc. London [Biol.] 185: 83-121.

Ellman, G. L., K. D. Courtney, V. Andres, Jr., and R. M. Featherstone (1961) A new and rapid colorimetric determination of acetylcholinesterase activity. Biochem. Pharmacol. 7: 88-95.

Fambrough, D. M. (1979) Control of acetylcholine receptors in skeletal muscle. Physiol. Rev. 59: 165-227.

Fernandez, H. L., M. J. Duell, and B. W. Festoff (1979) Neurotrophic control of $16 \mathrm{~S}$ acetylcholinesterase at the vertcbratc ncuromuscular junction, J. Neurobiol. 10: 441-454.

Gerschenfeld, H. M. (1973) Chemical transmission in invertebrate central nervous systems and neuromuscular junctions. Physiol. Rev. 53: $1-119$

Harrow, I. D., and D. B. Sattelle (1983) Acetylcholine receptors in the cell body membrane of giant interneurone 2 in the cockroach, Periplaneta americana. J. Exp. Biol. 105: 339-350.

Harrow, I. D., J. A. David, and D. B. Sattelle (1982) Acetylcholine receptors of identified insect neurons. Ciba Found. Symp. 88: 12-31.

Harrow, I. D., B. Hue, M. Pelhate, and D. B. Sattelle (1979) $\alpha$-Bungarotoxin blocks excitatory post-synaptic potentials in an identified insect interneurone. J. Physiol. (Lond.) 295: 63P-64P.

Hildebrand, J. G., L. M. Hall, and B. C. Osmond (1979) Distribution of binding sites for ${ }^{124}$ I-labclled $\alpha$-bungarotoxin in normal and deafferented antennal lobes of Manduca sexta. Proc. Natl. Acad. Sci. USA 76: 499-503.

Hoy, R. R., G. B. Casady, and S. Rollins (1978) Absence of auditory afferents alters the growth pattern of an identified auditory neuron. Soc. Neurosci. Abstr. 4: 115.

Jones, S. W., and K. Sumikawa (1981) Quinuclidinyl benzilate binding in house fly heads and rat brain. J. Neurochem. 36: 454-459.

Karnovsky, M. J., and L. Roots (1964) A "direct-coloring" thiocholine method for cholinesterases. J. Histochem. Cytochem. 12: 219-221.

Lamparter, H. E., K. Akert, and C. Sandri (1969) Localization of primary sensory afferents in the prothoracic ganglion of the wood ant (Formica lugubris Zett.): A combined light and electron microscopic study of secondary degeneration. J. Comp. Neurol. 137: 367-376.

Lecs, G., D. J. Beadle, and R. P. Botham (1983) Cholinergic receptors on cultured neurones from the central nervous system of embryonic cockroaches. Brain Res. 288: 49-59.

Levine, L. (1966) Tonicity of Acheta hemolymph. Physiol. Zool. 39; 253-258.

Lowry, O. H., N. J. Rosebrough, A. L. Farr, and R. J. Randall (1951) Protein measurement with the Folin phenol reagent. J. Biol. Chem. 193: 265-275.

McKinney, M., and J. T. Coyle (1982) Regulation of neocortical muscarinic receptors: Effects of drug treatment and lesions. J. Neurosci. 2: 97-105.

Meyer, M. R., and J. S. Edwards (1980) Muscarinic cholinergic binding sites in an orthopteran central nervous sytem. J. Neurobiol. 11:215219.

Meyer, M. R., and J. S. Edwards (1982) Metabolic changes in deafferented central neurons of an insect, Acheta domesticus. I. Effects upon amino acid uptake and incorporation. J. Neurosci. 2: 16511659.

Meyer, M. R., and G. R. Reddy (1985) Muscarinic and nicotinic cholinergic binding sites in the terminal abdominal ganglion of the cricket (Acheta domesticus). J. Neurochem. 45: 1101-1112.

Meyer, M. R., G. R. Reddy, and J. S. Edwards (1983) Sensory innervation regulates the level of cholinergic receptors on insect central neurons during postembryonic development. Soc. Neurosci. Abstr. 9: 320 .
Morrow, A. L., R. Loy, and I. Creese (1983) Septal deafferentation increases hippocampal adrenergic receptors: Correlation with sympathetic axon sprouting. Proc. Natl. Acad. Sci. USA 80: 6718-6722.

Murphey, R. K., and R. B. Levine (1980) Mechanisms responsible for changes observed in response properties of partially deafferented insect neurons. J. Neurophysiol. 43: 367-382.

Murphey, R. K., B. Mendenhall, J. Palka, and J. S. Edwards (1975) Deafferentation slows the growth of specific dendrites on identified giant interneurons. J. Comp. Neurol. 159: 407-418.

Palka, J., and J. S. Edwards (1974) The cerci and abdominal giant fibres of the house cricket, Acheta domesticus. II. Regeneration and effects of chronic deprivation. Proc. R. Soc. London [Biol.] 185: 105121.

Pitman, R. M., and K. Rand (1982) Neural lesions can cause dendritic sprouting of an undamaged adult insect motoneurone. J. Exp. Biol. 96: $125-130$.

Roeder, K. D., N. K. Kennedy, and E. A. Samson (1947) Synaptic conduction to giant fibers of the cockroach and the action of anticholinesterases. J. Neurophysiol. 10: 1-10.

Roederer, E., and M. J. Cohen (1983) Regeneration of an identified central neuron in the cricket. I. Control of sprouting from soma, dendrites, and axon. J. Neurosci. 3: 1835-1847.

Rotter, A., N. J. M. Birdsall, A. S. V. Burgen, P. M. Field, A. Smolen, and G. Raisman (1979) Muscarinic receptors in the central nervous system of the rat. IV. A comparison of the effects of axotomy and deafferentation on the binding of $\left[{ }^{3} \mathrm{H}\right]$-propylbenzilylcholine mustard and associated synaptic changes in the hypoglossal and pontine nuclei. Brain Res. Rev. 1: 207-224.

Sanes, J. R., D. J. Prescott, and J. G. Hildebrand (1977) Cholinergic neurochemical development of normal and deafferented antennal lobes during metamorphosis of the moth Manduca sexta. Brain Res. 119: 389-402.

Scatchard, G. (1949) The attractions of proteins for small molecules and ions. Ann. NY Acad. Sci. 51: 660-672.

Schmidt-Nielsen, B. K., J. I. Gepner, N. N. H. Teng, and L. M. Hall (1977) Characterization of an $\alpha$-bungarotoxin binding component from Drosophila melanogaster. J. Neurochem. 29: 1013-1029.

Schneiderman, A. M., S. G. Matsumoto, and J. G. Hildebrand (1982) Transsexually grafted antennae influence development of sexually dimorphic neurons in moth brain. Nature 298: 844-846.

Shaker, N., and A. Eldefrawi (1981) Muscarinic receptor in house fly brain and its interaction with chlorobenzilate. Pesticide Biochem. Physiol. 15: 14-20.

Shankland, M., D. Bentley, and C. S. Goodman (1982) Afferent innervation shapes the dendritic branching pattern of the medial giant interneuron in grasshopper embryos raised in culture. Dev. Biol. 92: 507-520.

Smith, D. E. (1977) The effect of deafferentation on the development of brain and spinal nuclei. Prog. Neurobiol. 8: 349-367.

Smith, D. S., and J. E. Treherne (1965) The electron microscopic localization of cholinesterase activity in the central nervous system of an insect, Periplaneta americana L. J. Cell Biol. 26: 445-459.

Taniguchi, T., K. Kurahashi, and M. Fujiwara (1983) Alterations in muscarinic cholinergic receptors after preganglionic denervation in the superior cervical ganglion in cats. J. Pharmacol. Exp. Ther, 224: 674-678.

Wigglesworth, V. B. (1958) The distribution of esterase in the nervous system and other tissues of the insect Rhodnius prolixus. Q. J. Microsc. Sci. 99: 441-450.

Yamamura, H. I., and S. H. Snyder (1974) Muscarinic cholinergic binding in rat brain. Proc. Natl. Acad. Sci. USA 71: 1725-1729. 